\title{
Publications Are Not the Finish Line: Focusing on Societal Rather Than Publication Impact
}

\author{
Farah R. W. Kools ${ }^{1 *}$, Sara Mirali ${ }^{2}$, Stephanie Holst-Bernal ${ }^{3}$, Sanne L. Nijhof ${ }^{4}$, \\ Giulio Cavalli ${ }^{5,6}$ and Michael A. Grandner ${ }^{7}$ \\ ${ }^{1}$ Center of Education and Training, University Medical Center Utrecht, Utrecht University, Utrecht, Netherlands, ${ }^{2}$ Institute of \\ Medical Science, Faculty of Medicine, University of Toronto, Toronto, ON, Canada, ${ }^{3}$ R2C-From Research to Community, \\ Eindhoven, Netherlands, ${ }^{4}$ Department of Pediatrics, Wilhelmina Children's Hospital, University Medical Center Utrecht, \\ Utrecht University, Utrecht, Netherlands, ${ }^{5}$ Unit of Immunology, Rheumatology, Allergy and Rare Diseases, San Raffaele \\ Hospital, Vita-Salute San Raffaele University, Milan, Italy, ${ }^{6}$ Department of Medicine, Radboud University Medical Center, \\ Nijmegen, Netherlands, ${ }^{7}$ Department of Psychiatry, College of Medicine, University of Arizona, Tucson, AZ, United States
}

Keywords: publication, society, impact, accountability, evaluation, translational medicine, interdisciplinary collaboration, scientific waste

\section{INTRODUCTION}

\section{OPEN ACCESS}

Edited by:

Berent Prakken,

Utrecht University, Netherlands

Reviewed by:

Coziana Ciurtin,

University College London, United Kingdom

Robert Adam Harris,

Karolinska Institutet (KI), Sweden

*Correspondence:

Farah R. W. Kools

f.r.w.kools-2@umcutrecht.nl

Specialty section

This article was submitted to

Translational Medicine,

a section of the journal

Frontiers in Medicine

Received: 30 September 2018

Accepted: 23 October 2018

Published: 12 November 2018

Citation:

Kools FRW, Mirali S, Holst-Bernal S, Nijhof SL, Cavalli G and Grandner MA (2018) Publications Are Not the Finish Line: Focusing on Societal Rather Than Publication Impact.

Front. Med. 5:314.

doi: 10.3389/fmed.2018.00314
Have bibliographical quantification of publications and the subsequent accompanying rewards perverted the incentives of scientists? Are we lost in a publish-or-perish research culture? Alarmingly, ample (bio)medical research findings intended to improve patient outcomes and lead to innovations in patient care never leave the lab (1-3). This widening gap between discovery and implementation undermines the social responsibility of scientists and erodes their public stature. When research findings have the potential to improve the health and well-being of society but are not translated into real-world benefits, it represents a failure of the system and a failure to society.

A re-evaluation of the parameters that define scientific success is imperative. Climbing the academic ladder and securing financial support relies heavily on a scientist's productivity, which is typically defined by the number of publications and their bibliometric scores $(4,5)$. Several groups are working toward developing novel measures for impact, but so far traditional bibliometric evaluation criteria prevail $(6,7)$. Whilst understandable that a quantitative system of evaluation might fulfill a desire for objectivity, this creates an intrinsically competitive culture in which regularly publishing ever-novel work is key to individual career success and open collaboration is undermined.

When novel discoveries are incentivized over refinement and implementation, it becomes strategically disadvantageous to do the work needed to translate discoveries into working strategies that benefit patients, the ultimate goal of translational medicine (1-3). Proper recognition and rewards for aiding efforts to achieve this goal must be advocated for, guided by the principles of social accountability and fostered by the support of key stakeholders (8).

\section{JOURNALS AS GATEKEEPERS}

One way in which the scientific community is not serving society well is reflected in the current publishing environment. The pressure to publish quantity over quality in order to build a successful scientific career has cultivated a rapidly-expanding ecosystem of thousands of journals publishing millions of papers per year (9). Many of these papers are seldom read or cited, and many contain non-reproducible or even fraudulent data $(10,11)$. Simultaneously, and partially because of the proliferating abundance of journals, there is increased pressure to publish in so-called "high-impact" journals, which have achieved recognition 
in the (bio)medical field as being highly desirable to publish in (12-16). Through their selection of what to publish and what not, these "high-impact" journals often become gatekeepers that define what is seen as "good" science by not only the research community, but also the general public. In an effort to impress the editors of these aggrandized journals, scientists increasingly focus on "cutting-edge" questions, rather than validating previous results or pushing them toward further development. Thus, there is a paradoxical problem of too many publications in too many journals, but also too much pressure to publish in too few journals. This creates a conflict where potential scientific advances are lost in the increasingly distracting background noise.

Similar to the role of the free press, scientific journals have a responsibility to the public: to objectively communicate advancements in scientific research and to foster productive exchange of ideas and information. How can journals fulfill this great responsibility? First, by realizing the impact their selection bias has and how strongly it shapes the global scientific research culture. Translational research cannot be accomplished by one individual at a time, it relies heavily on interdisciplinary collaboration and studies at all stages of the research pipeline deserve to be appreciated and rewarded. Second, by helping to shift the focus away from individual achievements and vacuous publication or citation counting, but conversely onto a common goal of achieving real societal impact through collaboration. Encouraging open-access platforms that provide full data sets helps ensure the full use of generated data, reducing scientific waste $(17,18)$. Web platforms could also implement new evaluation systems, rating scientists on their interdisciplinarity and collaborations. Finally, by revising the peer-review system. Despite holding a very important role in the publishing process, the current system offers little incentive for quality reviewing (19). Unmasking peer-review and rewarding the intellectual contribution and time dedicated by reviewers may promote a more fair process that is in line with the mission of the work. Adding an assessment of the potential for knowledge utilization and societal impact to be published alongside the article would also promote a healthier science culture.

If journals are gatekeepers through which all (bio)medical research must pass, it is time to redefine their role and influence. Translational medicine involves much work beyond initial discovery. The long and tedious but vitally important process of seeing research findings through to clinical practice is one of the field's most overwhelmingly difficult yet largely underappreciated burdens $(20,21)$.

\section{THE ROLE OF INDUSTRY, COMMUNITY AND OTHER STAKEHOLDERS}

In the case of (bio)medicine, there is a long and risky path from discovery to real-world clinical implementation (22). One research group cannot do all of this alone, especially since the later stages require partnership among many stakeholders (23, 24). If the goal of translational medicine is to implement research that has a meaningful societal impact, academia must collaborate more closely with all stakeholders involved, including industry, patients, and community leaders (6).

A current obstacle to translation is that partnerships among stakeholders are difficult to establish and maintain (25). Specifically, better partnerships between academia and industry would be instrumental to more time- and cost-efficient implementation of research findings (26). Although setting up shared platforms may demand sizeable initial investments, timely and continuing validation of research findings according to companies' pre-approved standards can save time and expenses at later stages of the translation process. More importantly, this facilitates a more efficient pipeline from discovery to societal benefit.

On a more individual scale, Technical Transfer Offices (TTOs), and similar programs housed within academic institutions can also help bridge the gap between academia and industry (27), yet this can be difficult if they are not involved early in the research process and do not remain engaged throughout. Therefore, academic institutions must create awareness amongst scientists and TTOs about their respective value. Specific programs, such as scouting systems to identify potentially impactful research findings, educational initiatives that promote the latest developments, and including TTOs as part of trans-institutional partnerships, might more efficiently establish a pipeline for ideas and networks including international collaborations. Funders could facilitate this by making an assessment of knowledge utilization and societal impact by a third party, e.g., TTO or patient organization, mandatory in annual reports. Sponsored networking events and training programs may also help overcome barriers and facilitate knowledge exchange between these key stakeholders. Developing a more collegial relationship based on shared goals can add momentum to this cooperative process and strengthen the scientific infrastructure as a whole.

Better engagement with other stakeholder groups will facilitate other aspects of the translational enterprise. Patient groups are an increasingly integral part of the scientific process, driving scientific questions (28-30). The voice of the patient in translational research is extremely important and must play a crucial role in the whole process (28). In a similar way, translational medicine has eschewed approaches such as community-based participatory research (CBPR) or community-engaged research (CER) (31, 32). These types of studies, which include community members in the generation of research questions and implementation of research studies, are a valuable approach toward improving the quality and value of the science itself. Involving the community may lead to the identification of underrecognized or underappreciated problems faced by the community, which in turn drives innovation. It may also serve to give a voice to underrepresented and disadvantaged groups that typically fall off the radar. These approaches not only improve scientific validity, innovation, and feasibility, but by including the community as a partner in the work, they kindle a bidirectional dialogue between scientists and society, which is ever more needed. 


\section{SCIENTIFIC COMMUNICATION}

Science in general is facing a growing problem of insufficient resources and eroding public appreciation (33-35). One reason for this is that the public, and funding bodies that often represent the public, are increasingly skeptical about the return on their investment $(33,36)$. A bench-to-bedside approach to research can help bridge gaps among basic discovery, clinical investigation, implementation, and application in society (37, 38). Effective communication with the public is an important part of this process.

As patients are increasingly confronted by misinformation and charlatanism, the public expresses a desire for clear-cut answers to what they perceive are clear-cut questions. But scientists notoriously provide overly-nuanced and seeminglyobfuscated conclusions. This creates a situation where media reporting of science tends toward overextrapolation and oversimplification which, in turn, leads to scientists being unenthusiastic about engagement with the media or public and the public's distrust of science growing as inaccuracies and exaggerations are borne out, e.g., "miracle cures" that aren't miracles. It is essential that scientists take on their role in guiding the scientific discourse. This is especially true in the field of translational medicine, where discoveries have the potential to directly impact lives.

Communicating science in a way that maintains accuracy, context, and nuance, is accessible to a non-scientific audience, and is as brief as a short news article is difficult, even for seasoned journalists. Additionally, journalists who are expected to cover a wide variety of topics often don't have the expertise or time to assess an individual study's relevance or integrity. It is up to the academics, who have a responsibility to maintain scientific integrity, to accurately interact with the press and advocate for appropriate representation of their work. If academics neglect this role, it will be filled by others who may not hold themselves to the same standards. Yet, scientists are often actively discouraged by peers from collaborating with the media. It is often seen as a distraction or, worse, as unprofessional. Currently though, the ability of scientists to engage the public is greater than it has ever been. More and more news outlets are seeking content, more people than ever are seeking information, and more direct lines of

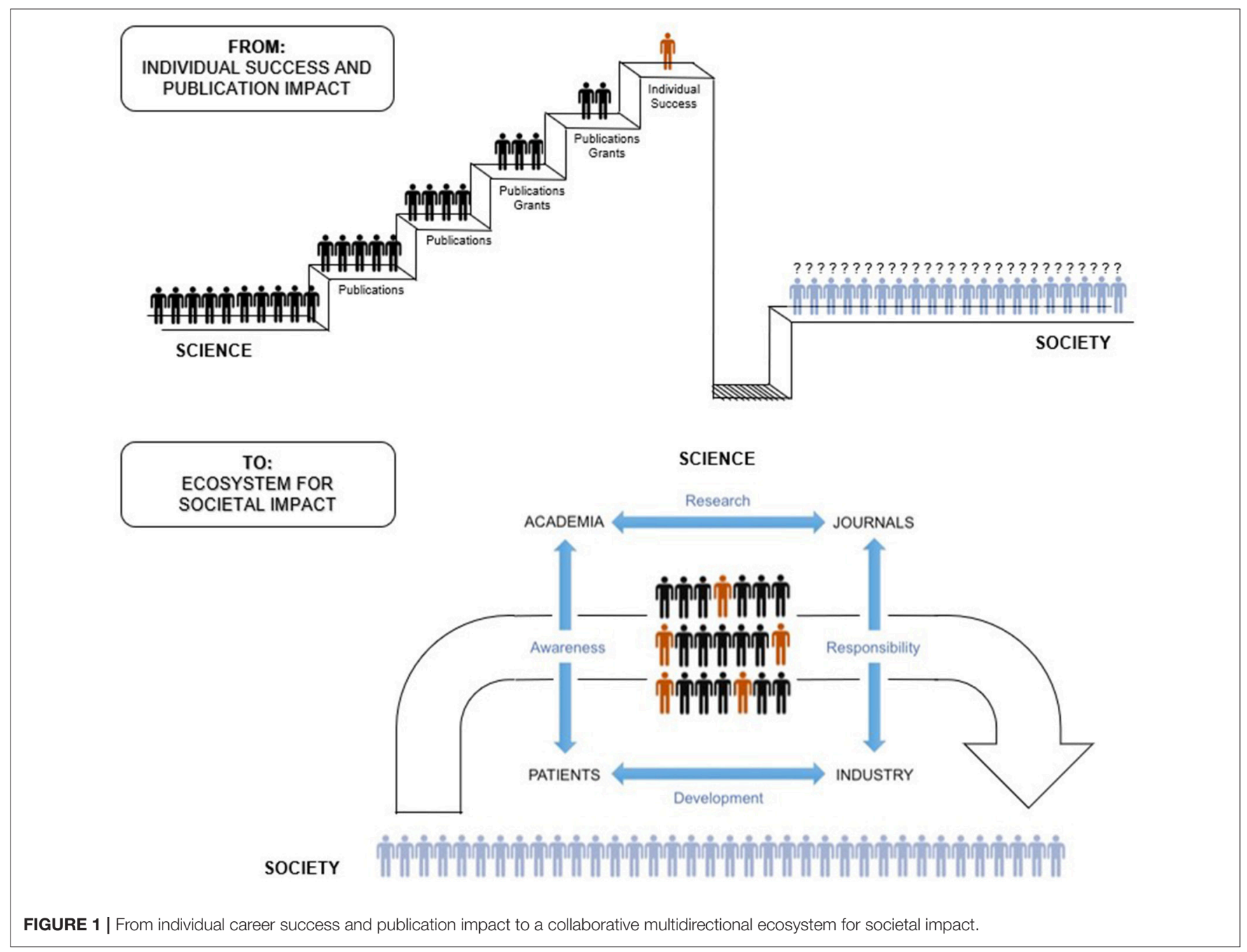


communication are available than there have ever been, e.g., social media.

Issues regarding scientific communication require initiatives at several levels. Academic institutions should better teach scientists how to communicate with the public, ensure that any press releases fairly represent their work, and also powerfully convey relevance to a lay audience. News organizations should collaborate more closely with academia to ensure that reported findings are not overly sensationalized. The public should be encouraged to engage with research with the understanding that while science is rigid in some ways, it reflects a constantly evolving process and an everchanging knowledge base. Improving scientific communication is a critical step in informing everyone, including patients and caregivers, on the relevance and merits of translational medicine. The importance of scientific literacy in communicating the societal impact of research is often and wrongfully neglected.

\section{CONCLUSION}

Society expects translational scientists to address relevant matters that aim to improve human health and well-being. Indeed, successful translational research has resulted in the clinical application of promising therapies such as CAR-T cell immunotherapy in leukemia and novel HIV antivirals $(39,40)$. However, the gap between society and academics is widening. Scientists find themselves enthralled in a vicious exercise: publish, secure funding, repeat. The public and other stakeholders are largely absent from this process. Scientists have become so accustomed to this unhealthy system, that they equate "success" with mere survival in the current publish-or-perish culture. Additionally, the perception of science by society and vice versa is dangerously perturbed.

\section{REFERENCES}

1. Fernandez-Moure JS. Lost in translation: the gap in scientific advancements and clinical application. Front Bioeng Biotechnol. (2016) 4:43. doi: 10.3389/fbioe.2016.00043

2. Fang FC, Casadevall A. Lost in translation-basic science in the era of translational research. Infect Immun. (2010) 78:563-6. doi: 10.1128/IAI.01318-09

3. Curran T. Lost in translation: the future of cancer research? Clin Cancer Res. (2005) 11:4644-5. doi: 10.1158/1078-0432.CCR-05-0333

4. Alonso S, Cabrerizo FJ, Herrera-Viedma E, Herrera F. hg-index: a new index to characterize the scientific output of researchers based on the hand g-indices. Scientometrics (2010) 82:391-400. doi: 10.1007/s11192-0090047-5

5. Bornmann L, Marx W. How to evaluate individual researchers working in the natural and life sciences meaningfully? A proposal of methods based on percentiles of citations. Scientometrics (2014) 98:487-509. doi: 10.1007/s11192-013-1161-y

6. Ozanne JL, Davis B, Murray JB, Grier S, Benmecheddal A, Downey H, et al. Assessing the Societal Impact of Research: The Relational Engagement Approach. J. Public Policy Mark. (2017) 36:1-14. doi: 10.1509/jppm.14.121

7. Ravenscroft J, Liakata M, Clare A, Duma D. Measuring scientific impact beyond academia: An assessment of existing impact metrics and proposed improvements. PLoS ONE (2017) 12:e0173152. doi: 10.1371/journal.pone. 0173152
Breaking free from the current failing system will require disrupting this vicious cycle and realigning (bio)medical research with its original mission (Figure 1). This requires reconsideration of the publication system and strategies for including important stakeholders throughout the process. Society must be better informed about the importance of research and play a larger role in its advancement. To accomplish this, scientists and other stakeholders need to take more responsibility in facilitating discussion in a way that effectively communicates and serves the public, while maintaining scientific integrity. Translational scientists should also remember the societal context of their work, recognizing their social accountability and the need for proper two-way dialogue with the public, driving innovation in both directions.

In conclusion, publication should not be the finish line scientists strive to, it should be a stepping stone toward a greater good.

\section{AUTHOR CONTRIBUTIONS}

FK, SM, and SH-B conducted literature research and authored the manuscript. SN and GC advised and guided the writing process. MG revised and edited the final manuscript.

\section{FUNDING}

MG was supported by NIH grant R01MD011600.

\section{ACKNOWLEDGMENTS}

The authors would like to thank Prof. Dr. Berent Prakken and the Eureka Institute for Translational Medicine for the opportunity to be part of this research topic.

8. van den Akker W, Spaapen J. Productive interactions: societal impact of academic research in the knowledge society. LERU position Pap. (2017).

9. Ware M, Mabe M. The STM report, 4th edn. STM (2015). doi: 10.1017/CBO9781107415324.004

10. Baker M, Penny D. Is there a reproducibility crisis? Nature (2016) 533:452-4. doi: 10.1038/533452a

11. Munafò MR, Nosek BA, Bishop DVM, Button KS, Chambers CD, du Sert NP,et al. A manifesto for reproducible science. Nat Hum Behav (2017) 1:0021. doi: 10.1038/s41562-016-0021

12. Tijdink JK. Publish and Perish: research on research and researchers. Dissertation (2016).

13. Alberts B, Kirschner MW, Tilghman S, Varmus H. Rescuing US biomedical research from its systemic flaws. Proc Natl Acad Sci USA. (2014) 111:5773-7. doi: 10.1073/pnas.1404402111

14. Cyranoski D, Gilbert N, Ledford H, Nayar A, Yahia M. The PhD factory. Nature (2011) 472:276-9. doi: 10.1038/472276a

15. Fang FC, Casadevall A. Competitive science: is competition ruining science? Infect Immun. (2015) 83:1229-33. doi: 10.1128/IAI.02939-14

16. Ridker PM, Rifai N. Expanding options for scientific publication: is more always better? Circulation (2013) 127:155-6. doi: 10.1161/CIRCULATIONAHA.112.155952

17. Granqvist E. Why Sience Needs to Publish Negative Results. Amsterdam: Elsevier (2015).

18. Vickers AJ. Whose data set is it anyway? Sharing raw data from randomized trials. Trials (2006) 7:15. doi: 10.1186/1745-6215-7-15 
19. Vale RD. Evaluating how we evaluate. Mol Biol Cell. (2012) 23:3285-9. doi: 10.1091/mbc.e12-06-0490

20. Woolf SH. The meaning of translational research and why it matters. JAMA (2008) 299:211-3. doi: 10.1001/jama.2007.26

21. Lenfant C. Clinical research to clinical practice - lost in translation? N Engl J Med. (2003) 349:868-74. doi: 10.1056/NEJMsa035507

22. Ioannidis JPA. Biomarker failures. Clin Chem. (2013) 59:202-4. doi: 10.1373/ clinchem.2012.185801

23. Begley CG, Ellis LM. Drug development: raise standards for preclinical cancer research. Nature (2012) 483:531-3. doi: 10.1038/ 483531a

24. Rubio DM, Schoenbaum EE, Lee LS, Schteingart DE, Marantz PR, Anderson $\mathrm{KE}$, et al. Defining translational research: implications for training. Acad Med. (2010) 85:470-5. doi: 10.1097/ACM.0b013e3181 ccd618

25. Pasterkamp G, Hoefer I, Prakken B. Lost in the citation valley. Nat Biotechnol. (2016) 34:1016-8. doi: 10.1038/nbt.3691

26. Van Gool AJ, Bietrix F, Caldenhoven E, Zatloukal K, Scherer A, Litton JE, et al. Bridging the translational innovation gap through good biomarker practice. Nat. Rev. Drug Discov. (2017) 16:587-88. doi: 10.1038/nrd.2017.72

27. Sadek T, Kleiman R, Loutfy R. The role of technology transfer offices in growing new entrepreneurial ecosystems around mid-sized universities. Int J Innov Reg Dev. (2015) 6:61-79. doi: 10.1504/IJIRD.2015.067648

28. Tshomba Y, Cavalli G. Priorities of biomedical research. Int J Cardiol. (2017) 245:256. doi: 10.1016/j.ijcard.2017.07.073

29. Sacristan JA, Aguarón A, Avendaño-Solá C, Garrido P, Carrión J, Gutiérrez A, et al. Patient involvement in clinical research: why, when, and how. Patient Prefer Adherence. (2016) 10:631-40. doi: 10.2147/PPA.S104259

30. Laine C, Davidoff F. Patient-centered medicine: a professional evolution. JAMA (1996) 275:152-6. doi: 10.1001/jama.1996.035302600 66035

31. Wallerstein N, Duran B. Community-based participatory research contributions to intervention research: the intersection of science and practice to improve health equity. Am J Public Health (2010) 100:S40-6. doi: 10.2105/AJPH.2009.184036

32. Michener L, Cook J, Ahmed SM, Yonas MA, Coyne-Beasley T, AguilarGaxiola S. Aligning the goals of community-engaged research: why and how academic health centers can successfully engage with communities to improve health. Acad Med. (2012) 87:285-91. doi: 10.1097/ACM.0b013e31824 41680
33. Tallon D, Chard J, Dieppe P. Relation between agendas of the research community and the research consumer. Lancet (2000) 355:2037-40. doi: 10.1016/S0140-6736(00)02351-5

34. Moses H, Matheson DH, Cairns-Smith S, George BP, Palisch C, Dorsey ER, et al. The anatomy of medical research. JAMA (2015) 313:174-89. doi: 10.1001/jama.2014.15939

35. Gollust SE, Seymour JW, Pany MJ, Goss A, Meisel ZF, Grande D. Mutual distrust: perspectives from researchers and policy makers on the research to policy gap in 2013 and recommendations for the future. J Heal Care (2017) 54:46958017705465. doi: 10.1177/0046958017705465

36. Jensen JD, Hurley RJ. Conflicting stories about public scientific controversies: effects of news convergence and divergence on scientists' credibility. Public Underst. Sci. (2012) 21:689-704. doi: 10.1177/0963662510387759

37. van der Laan AL, Boenink M. Beyond bench and bedside: disentangling the concept of translational research. Heal Care Anal. (2015) 23:32-49. doi: 10.1007/s10728-012-0236-x

38. Drolet BC, Lorenzi NM, Nashville A. Translational research: understanding the continuum from bench to bedside. Transl Res. (2011) 157:1-5. doi: 10.1016/j.trsl.2010.10.002

39. Fesnak $\mathrm{AD}$, June $\mathrm{CH}$, Levine $\mathrm{BL}$. Engineered $\mathrm{T}$ cells: The promise and challenges of cancer immunotherapy. Nat Rev Cancer. (2016) 16:566-581. doi: $10.1038 /$ nrc. 2016.97

40. Saag MS, Benson CA, Gandhi RT, Hoy JF, Landovitz RJ, Mugavero MJ, Sax $\mathrm{PE}$, et al. Antiretroviral drugs for treatment and prevention of HIV infection in adults. JAMA (2018) 320:379. doi: 10.1001/jama.2018.8431

Conflict of Interest Statement: The authors declare that the research was conducted in the absence of any commercial or financial relationships that could be construed as a potential conflict of interest.

The handling editor declared a shared affiliation, though no other collaboration, with one of the authors FK at time of review.

Copyright (c) 2018 Kools, Mirali, Holst-Bernal, Nijhof, Cavalli and Grandner. This is an open-access article distributed under the terms of the Creative Commons Attribution License (CC BY). The use, distribution or reproduction in other forums is permitted, provided the original author(s) and the copyright owner(s) are credited and that the original publication in this journal is cited, in accordance with accepted academic practice. No use, distribution or reproduction is permitted which does not comply with these terms. 